\title{
Freeman-Burian syndrome
}

\author{
Mikaela I. Poling ${ }^{1 *}$ (D), Craig R. Dufresne ${ }^{2}$ and Robert L. Chamberlain ${ }^{1 \wedge}$
}

\begin{abstract}
Clinical description: Freeman-Burian syndrome (FBS) is a rare congenital myopathic craniofacial syndrome. Considerable variability in severity is seen, but diagnosis requires the following: microstomia, whistling-face appearance (pursed lips), H or V-shaped chin defect, and prominent nasolabial folds. Some patients do not have limb malformations, but essentially all do, typically camptodactyly with ulnar deviation of the hand and talipes equinovarus. Neuro-cognitive function is not impaired.

Epidemiology: Population prevalence of FBS is unknown.

Aetiology: Environmental and parental factors are not implicated in pathogenesis. Allelic variations in embryonic myosin heavy chain gene are associated with FBS. White fibrous tissue within histologically normal muscle fibres and complete replacement of muscle by fibrous tissue, which behaves like tendinous tissue, are observed.

Management: Optimal care seems best achieved through a combination of early craniofacial reconstructive surgery and intensive physiotherapy for most other problems. Much of the therapeutic focus is on the areas of fibrous tissue replacement, which are either operatively released or gradually stretched with physiotherapy to reduce contractures. Operative procedures and techniques that do not account for the unique problems of the muscle and fibrous tissue replacement have poor clinical and functional outcomes. Important implications exist to facilitate patients' legitimate opportunity to meaningfully overcome functional limitations and become well.

Keywords: Freeman-Sheldon syndrome, Whistling face syndrome, Craniocarpotarsal dystrophy, Craniocarpotarsal dysplasia, Distal arthrogryposis type 2A, Embryonic myosin heavy chain, Craniofacial syndrome, Distal arthrogryposis
\end{abstract}

\section{Background}

\section{Disease name and synonyms}

Freeman-Burian syndrome (FBS): MIM 193700, ICD-10 Q87.0, ORPHA 2053; Freeman-Sheldon syndrome, craniocarpotarsal dystrophy; craniocarpotarsal dysplasia; whistling face syndrome; distal arthrogryposis type $2 \mathrm{~A}$.

\section{Definition}

Freeman-Burian syndrome (FBS) is a rare congenital myopathic craniofacial syndrome $[1,2]$. Considerable variability in severity is seen, but diagnosis requires the following: microstomia, whistling-face appearance (pursed lips), $\mathrm{H}$ or $\mathrm{V}$-shaped chin defect, and prominent nasolabial folds (Fig. 1). Some patients do not have limb malformations, but essentially all do, typically camptodactyly with ulnar deviation of the hand and talipes equinovarus. Relatively little is known about FBS (Fig. 1). FBS is first described by

\footnotetext{
*Correspondence: poling_mi@fsrgroup.org

Deceased

${ }^{1}$ FSRG deGruyter-McKusick Institute of Health Sciences, Buckhannon, USA Full list of author information is available at the end of the article
}

Freeman and Sheldon (1938) [3], and independent confirmation of a distinct pathological entity is provided by Burian (1963) [4], who coined the memorable 'whistling face' descriptor.

\section{Nomenclature}

Since its first description [3], the nomenclature of the syndrome has remained problematic, with no less than six synonyms having been asserted [1]. The term Freeman-Burian syndrome has been suggested to replace Freeman-Sheldon syndrome [1]. Among other benefits, the new eponym avoids confusion with the distinct but phenotypically similar Sheldon-Hall syndrome (SHS; MIM 601680) and highlighting the syndrome's pathognomonic craniofacial features at one stroke by the use of Francis Burian's surname rather the Joseph Harold Sheldon's [1, 3, 4].

\section{Epidemiology}

Due to insufficient data and diagnostic and nomenclature ambiguity, the true population prevalence of FBS is unknown. A prevalence frequency of 0.9 per 1 million is 


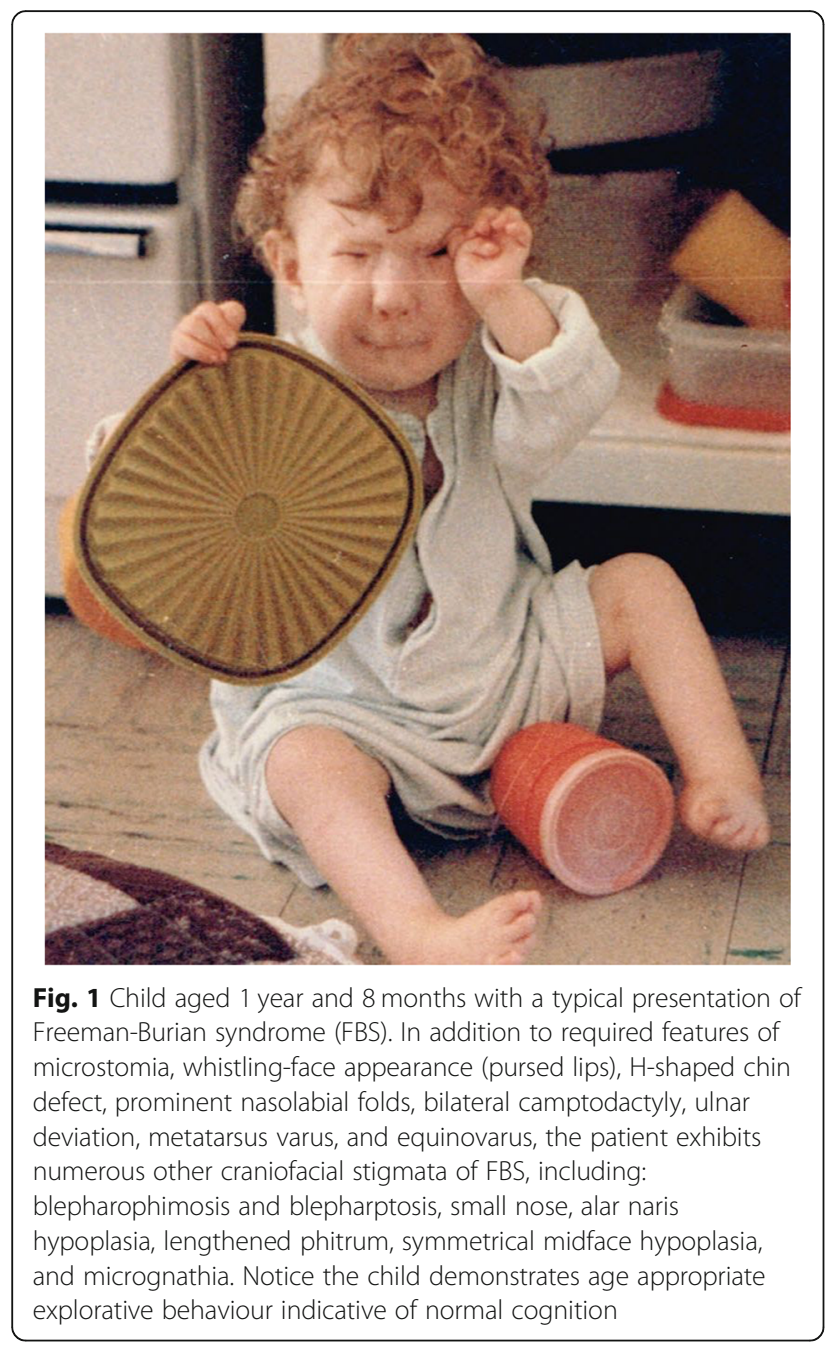

accepted [5], but there is disagreement about this. There appears to be neither gender, ethnic, nor geographical preference.

\section{Clinical description}

In addition to findings required for diagnosis, many craniofacial problems (Table 1) are seen. Many patients have a long, mask-like facial appearance. Several limb malformations (Table 2) are accepted in the diagnostic criteria of FBS that overlap with the distal arthrogryposes. The intercostal muscles are non-functional in some patients, with the diaphragm changing intrathoracic volume [6]. There is the potential for restrictive pulmonary disease progressing to right heart failure [7]. Scoliosis, lordosis, kyphosis, and visual and auditory impairments are relatively common findings. Other problems (Table 3) are known to occur frequently but are not understood and poorly characterised. Overall, some individuals present with minimal malformation, while others show profound and striking facial stigmata, severe extremity contractures, and markedly abnormal spinal curvatures. Delayed growth in childhood and adolescence is almost universal, but intelligence is normal.

\section{Neonatal and early childhood health concerns}

Respiratory complications are common during the perinatal and neonatal period but are under-reported in the literature. Idiopathic febrile and apnoeic episodes occur sometimes in infancy and early childhood. Developmental delays may be present in a number of areas, secondary to varying degrees of physical limitations (Ritchie SK. Personal communication. 29 July 2005). Infancy may be characterised by failure-to-thrive for many patients with FBS due to associated dysphagia, microstomia, micrognathia, high palate, and microglossia. An initial soft diet and frequent feeding of small volume is typically required. Though not expressly referenced in the literature, many patients present with a thin habitus and small stature in childhood. Inguinal hernia may also be seen $[8,9]$. Difficulties encountered in infancy seem to stabilise and improve with age for most patients.

\section{Aetiology}

Environmental and parental factors, excluding potential for germinal mosaicism, are not implicated in pathogenesis. Allelic variations in embryonic myosin heavy chain (MYH3; MIM 160720) gene are associated with FBS [10]. In one study, twenty-eight patients have been screened (21 sporadic and 7 inherited) probands [10]. In 20 patients (12 and 8 probands, respectively), de novo missense allelic variations (R672H and R672C) cause

Table 1 Possible craniofacial anatomical features seen in Freeman-Burian syndrome, excluding those required for diagnosis

\begin{tabular}{lll}
\hline scaphocephaly & enophthalmos & epicanthal folds \\
low hairlines & ocular hypertelorism & strabismus \\
blepharophimosis & upper blepharoptosis & small nose \\
alar naris hypoplasia & two subcutaneous mounds & horizontal skeletal elevation \\
& paralleling frontal hairline \\
prominent supraorbital ridge & down-slanting palpebral fissures & long philtrum \\
midface hypoplasia & high arched hard palate & class II malocclusion \\
dental crowding & microglossia & micrognathia \\
straight mandibular rami & pterygium of the neck & limited range of motion of the neck \\
\hline
\end{tabular}


Table 2 Distal extremity malformations (two or more required) fulfilling the accepted criteria for Freeman-Burian syndrome

\begin{tabular}{lll}
\hline talipes equinovarus & metatarsus varus & talipes equinovalgus \\
vertical talus & calcaneovalgus & camptodactyly \\
$\begin{array}{l}\text { ulnar deviation of } \\
\text { wrists / fingers }\end{array}$ & $\begin{array}{l}\text { overlapping } \\
\text { fingers or toes }\end{array}$ & hypoplastic or absent \\
interphalangeal creases
\end{tabular}

substitution of arginine at position 672 (arg672) by histidine (N 8) and cytosine (N 12); arg672 is found in all myosin proteins post-embryonically [10]. Of the remaining six patients in whom allelic variations are found, three have missense private de novo (E498G and Y583S) or familial allelic variations (V825D); three other patients with sporadic expression have de novo allelic variations (T178I), which is also found in two cases of SHS [10]. Two FBS patients show no recognised allelic variations [10].

\section{Functional genetics}

The most common FBS-associated allelic variations appear to disrupt adenosine triphosphate (ATP) binding to MYH3 and are suggested to influence myophysiology during early development, producing joint contractures due to haploinsufficiency of MYH3's product and eventual downregulation, retarding muscle development, and leaving residual defects $[10,11]$. Muscle cells and myofibrils from patients with FBS show attenuated specific force, lengthened time to relaxation, and higher baseline residual force, caused by presence of fewer myosin cross-bridges and attenuated detachment kinetics [12]. There is also slow and incomplete deactivation of thin filaments during the latter part of contraction [12]. ATP hydrolysis is prolonged five to nine times normal range, delaying subsequent metabolic action [13]. The MYH3 allelic variations Y583S and T178I expressed in Drosophila result in extreme muscular stiffness, causing a $45 \%$ reduction in work and $62 \%$ in maximal power [14].

\section{Operative findings}

In patients with FBS, white fibrous tissue within histologically normal muscle fibres and complete replacement of muscle by fibrous and adipose tissue is observed operatively $[1,15]$. In some areas, entire muscles are

Table 3 Other problems that appear to occur with higher frequencies in Freeman-Burian syndrome

\begin{tabular}{lll}
\hline sleep apnoea & hyperpyrexia & dysglycaemia \\
hyperhidrosis & constipation & diarrhoea \\
vomiting & $\begin{array}{l}\text { gastrointestinal oesophageal } \\
\text { reflux disease }\end{array}$ & \\
\hline
\end{tabular}

grossly and histologically normal $[1,15]$. There may be variable syndromic affectation in different body regions and possibly down to muscle groups or individual muscles $[1,15]$. The areas of fibrous tissue replacement behave like tendinous tissue, which is often released to reduce the contractures [1]. Operative findings in FBS correlate well with in vitro molecular myophysiology observations [1, 12-14]. Blepharophimosis may be precipitated by blepharospasm earlier in development, when muscle in the eyelid is present [15]. This muscle tissue is destroyed-probably at the neuromuscular junction levelcausing connective and adipose tissue replacement [15].

\section{Diagnosis}

The current FBS diagnostic criteria is based on physical findings [16], and there is strong agreement with associated $M Y H 3$ allelic variations [10]. The presence of a group of craniofacial physical findings (whistling face, microstomia, prominent nasolabial folds, and $\mathrm{H}$ or V-shaped chin defect) is pathognomonic for FBS, with the presence or absence of limb deformities being secondary and non-diagnostic factors [2]. Findings in this group of craniofacial findings are not individually pathognomonic. While possible, molecular testing may be non-diagnostic, as at least $7 \%$ of clinical FBS cases are not explained by known pathological allelic variations [10], and allelic variations may be found for which little or no clinical data exist.

\section{Differential diagnosis}

Differential diagnosis of FBS can be fraught with difficulty, due to wide clinical variability of presentations, both in terms of severity and physical findings and history demonstrated by patients. Distal arthrogryposis types $1 \mathrm{~A}, 1 \mathrm{~B}, 2 \mathrm{~B}, 3,7$, and 8; Schwartz-Jampel syndrome; and non-syndromic distal contractures can resemble aspects of FBS. Appropriate treatment is dependent on correct diagnosis. While a multitude of findings frequently found in patients with FBS may be present in a given patient, only those of diagnostic importance should be the focus of initial attention. For patients with congenital malformations, presence of the pathognomonic craniofacial findings for FBS should prompt provisional FBS diagnosis-irrespective of the presence or absence of any other findings-and referral of the patient to a craniofacial clinic for evaluation and management to ensure optimal outcomes. The presence of whistling face (pursed lips) alone or in combination with limb malformations is not diagnostic, and FBS is genotypically unique from somewhat phenotypically similar distal arthrogryposes, chiefly Sheldon-Hall syndrome, without any common molecular genetic features $[10,17,18]$. 


\section{Neurogenic syndromes}

Congenital contractures of the limbs and face, hypotonia, and developmental delay (CLIFAHDD; MIM 616266) is a distinct autosomal dominant lethal condition distinguished from FBS by profound and progressive neurological motor and cognitive impairment [19]. At least 14 different allelic variations in the pore-forming area (S5 and S6 segments) of the sodium leak channel, non-selective (NALCN; MIM 611549) gene are associated with CLIFAHDD [19]. All patients with CLIFAHDD [20, 21] are suggested to have de novo sporadic heterozygous allelic variations [19]. There may e overlap of CLIFAHDD with Illum syndrome (MIM 208155), lethal whistling face with limb deformities, but both are distinct from FBS.

\section{Sheldon-hall syndrome}

Often confused with FBS and once termed Freeman-Sheldon variant, SHS exhibits a similar phenotype as classic FBS, but patients lack severe microstomia and history of dysphagia and display a triangularly shaped face; small, prominent chin; and equinovalgus [16]. In FBS, patients show an elongated face, severe microstomia, micrognathia, and equiniovarus [16]. Generally, SHS is considered less severe than FBS [16]. Inheritance in SHS is autosomal dominant [16]. SHS is associated with allelic variations in the fast skeletal muscle troponin $\mathrm{T}$ and I gene (TNNT3 and TNNI2; MIM 600692 and 191,043) [22], tropomyosin beta chain gene (TPM2; MIM 190990) [23], and MYH3 [10]. SHS-associated allelic variations R174Q and R156X on TNNI2 gene and R63H on TNNT3 gene are associated with increased ATPase activity, suggesting increased calcium sensitivity and increased contractility [24].

\section{Other phenotypically similar syndromes}

Distal arthrogryposis type 1A (MIM 108120) and distal arthrogryposis type 1B (MIM 614335) strongly resemble the limb malformations of FBS and SHS but lack craniofacial features. Both also demonstrate an autosomal dominant inheritance pattern and are caused by allelic variations of the TMP2 gene. Distal arthrogryposis type 3 or Gordon syndrome (MIM 114300) is considered distal arthrogryposis type 1 with additional features, including: cleft palate, blepharoptosis, and abnormal spinal curvatures, again lacking specific craniofacial findings of either FBS or SHS. Gordon syndrome is associated with allelic variations on the piezo type mechanosensitive ion channel component 2 gene (PIEZO2; MIM 613629) [25]. Arthrogryposis multiplex congenita is a distinct entity from FBS and the conditions collectively known as distal arthrogryposes.

Some phenotypical overlap for FBS also exists with Schwartz-Jampel syndrome (MIM 255800), distal arthrogryposis type 7 or trismus-pseudocamptodactyly syndrome
(MIM 158300), and distal arthrogryposis type 8 or multiple pterygium syndrome (MIM 178110). Schwartz-Jampel syndrome is distinguished from FBS by myotonic myopathy, which is not present in FBS, though joint, spine, and eye problems may be similar to FBS. While patients with trismus-pseudocamptodactyly syndrome have limited mouth opening, they lack true microstomia. Pseudo-camptodactyly is also a distinguishing feature not present in FBS, though micrognathia, dysphagia, and a long philtrum occur in FBS and trismus-pseudocamptodactyly. FBS and multiple pterygium syndrome share pterygium of certain joints, though this finding is much more prominent in the latter condition.

\section{Antenatal diagnosis}

For women with FBS wishing to prevent an FBS pregnancy, pre-conception testing of polar bodies is possible with targeted allelic variation testing of the MYH3 gene (unpublished data). MYH3 targeted allelic variation screening can also be accomplished post-conception. As $7 \%$ of clinical FBS phenotypes are unaccounted for by currently documented allelic variations [10], screening could be non-diagnostic. For those who may be at risk for having a child with FBS, prenatal ultrasound can be useful, but confirmed ultrasound diagnosis has not been reported before 20 weeks' gestation [26, 27]. Polyhydramnios and decreased foetal movements are sometimes reported. When there is a positive family history, a normal ultrasound does not exclude FBS. Abortion in the case of suspected FBS, however, is not recommended due to the non-lethal, non-progressive, and non-cognitively impairing hallmarks of FBS. Most pregnancies and deliveries involving FBS patients are uncomplicated, with some births via spontaneous vaginal delivery reported.

\section{Genetic counselling}

As most instances of FBS are sporadic, genetic counselling is not generally recommended for patients who have a child with FBS but may be offered. Autosomal dominant inheritance is accepted and has a $50 \%$ risk of transmission. Suggested instances of autosomal recessive inheritance (MIM 277720) and are better explained by germline mosaicism [28]; in suspicious cases, genetic counselling and molecular testing may be helpful.

\section{Molecular testing}

There is no diagnostic or therapeutic benefit of molecular testing for individuals with FBS clinical phenotype. Due to a lack of clinical correlation data on different potentially pathological genotypes, molecular testing cannot confirm diagnosis, unless a previously correlated genotype is found in the individual. While efforts have 
been made to correlate natural history and diagnosis with specific genotypes [11, 18], this level of detailed information does not exist outside of a couple of genotypes studied; thus, the resulting genotype generally cannot be used, at this point, to individualise therapy. Genetic therapies, in and of themselves, are very distant. Although offered as a clinical test, the utility of molecular testing in individuals with a FBS clinical phenotype is purely from its value as a research tool, and families should not be misled. Reliable and repeatable diagnosis originates from the presence of the pathognomonic group of craniofacial stigmata (whistling face, microstomia, prominent nasolabial folds, and $\mathrm{H}$ - or $\mathrm{V}$-shaped chin defect), and results of molecular testing do not, at this time, add useful clinical data.

\section{Management}

There is no specific treatment for FBS. There is little in the literature on medical management beyond infancy, but operative intervention is universal, with a great diversity of operative procedures described. Reported surgical interventions often lack procedural details or long-term follow-up. Difficult anaesthesia is well-documented, and clinical practice guidelines are available [29]. Patients with FBS frequently undergo numerous orthopaedic surgeries, because attempts at operative deformity correction have suboptimal results and require subsequent revision. The best results for limb malformations are achieved with non-operative intervention. Even craniofacial surgeries, which often have better outcomes, require revision after eventual reformation of fibrous tissue contracting bands within normal muscle.

\section{Anaesthesia}

The anaesthetic management of patients with FBS is complicated by orofacial contractures, limited neck mobility, spinal deformities, and difficult vascular access [29]. Though it is suggested that up to $50 \%$ of patients with FBS are malignant hyperthermia $(\mathrm{MH})$ susceptible, this is not substantiated by more recent reports [3]. Nevertheless, an MH-safe anaesthetic technique is standard for FBS patients [29]. The published anaesthesia management protocol includes an enumeration of potential challenges and complications in FBS patients [29], a discussion of which is beyond the scope of this review.

\section{Craniofacial surgeries}

Oral commissuroplasties for microstomia correction to facilitate oro-tracheal intubation, dental treatment, oral hygiene, speaking, and oral nutrition are the most common surgery overall [30-40]. Repeated myringotomies with pressure equalisation tube placement is discussed [35, 37, 41, 42]. Correction of alar nasi hypoplasia with V-Y advancement flaps is discussed [4, 37]. Modified bilateral therapeutic blepharoplasty with a static sling to the epicranious frontalis for blepharophimosis and blepharoptosis is described, with stable results at 9-year follow-up [15]. Other approaches to blepharophimosis and blepharoptosis are described, including: complete forehead reshaping and use of a static sling to the epicranious frontalis [36], static sling to the frontalis without procedural details [35], and bilateral canthoplasties [43]. Strabismus correction [9, 36], dental extractions [15, 44], dental implant insertion [39], and frenectomy and choanal atresia repair [37] are also reported.

\section{Hand surgery}

Multiple authors discuss hand reconstruction [9, 32, 45, 46], which generally does not result in stable long-term results, but therapeutic outcome is likely due more to suboptimal patient compliance with occupational therapy. Most hand procedures include first webspace widening, capsulotomies, and tendon releases and lengthening.

\section{Lower extremity surgeries}

Operative correction of lower extremity deformities generally results in unfavourable results $[3,9,33,35,36,47-52]$. McCormick et al. (2015) describe a patient that required multiple full-thickness skin grafting after failed bilateral equinovarus correction, lost functional use of the feet, was confined to a wheelchair for fifteen years, and eventually was fitted with bilateral Symes-type lower extremity prostheses without amputation [53]. Unsuccessful surgical release of knee contractures [48] and open reduction of congenital hip dislocations $[48,51]$ are also described.

\section{Other surgeries}

Correction of spinal deformities is mentioned [54], with one patient requiring HALO traction [48]. Correction of pedal polydactylism [43], ureteric reimplantation [55], aortic valve replacement in a 64-year-old man with multiple non-syndromic cardiovascular comorbidities [56], resection of gangrenous testes [3], and resection of an ovarian cyst and bilateral salpingectomy [9] are also mentioned in the literature.

\section{Non-operative therapy, psychosocial concerns, and longitudinal care}

While surgical intervention is inevitable in FBS patients, the Ponseti method is described to correct equinovarus in FBS and distal arthrogryposis syndromes [57]. In FBS and distal arthrogryposis patients, post-therapeutic bracing is usually required to maintain correction beyond the average 4 years of therapy for patients without FBS or distal arthrogryposis (Ponseti IV. Personal communication. 3 January 2007). Two successful 3-month proof-of-concept trials of intensive passive manipulation and bracing for 
correction of multiple chronic bilateral hand and wrist deformities in an adult female patient with classic FBS is described [58]. Few authors mention psychosocial function in FBS, and none discuss psychiatric care or the impact on families. Poor self-image; feelings of inadequacy, anger, and rage; post-traumatic stress disorder; and depression associated with FBS have been described [34, 42]. In addition to depression and disorders of traumatic aetiology, some patients with FBS develop social anxiety, substance abuse, and maladaptive sexual behaviours. It is also probable that at least some of the gastroenterological problems attributed to physiological aberrations of FBS have a psychosomatic aetiology. Importantly, patients with FBS exhibit greatly reduced facial animation, providing limited non-verbal cues to appraise their affect, a factor that has to be considered when assessing fear, anxiety, and pain in patients with FBS. Overall, long-term management should not focus exclusively on health maintenance but on continual improvement of functional outcomes. This important distinction is often overlooked, resulting in missed opportunities to help patients.

\section{Prognosis}

Several findings and treatment modalities are predictive of overall clinical outcome. In FBS, lower extremity contractures-classically manifested as equinovarus, metatarsus varus, and vertical talus-are associated with poor mobility outcomes without appropriate non-surgical manipulative and rehabilitative interventions. Patients with FBS, who have such lower extremity contractures and are ambulatory, frequently require assistive devices or have some degree of impairment or discomfort. Spinal curvatures may not be responsive to surgical intervention that does not accommodate the myopathy of FBS and progress if left untreated. Patients with severe and progressive abnormal spinal curvatures can have poor long-term clinical outcomes for both pulmonary and gastrointestinal function and greatly diminished occupational and quality of life outcomes. Hand and wrist contractures are also reported as being mostly treatment-resistant, if bracing and physiotherapy are not maintained.

In hand and wrist, ankle and foot, and spinal deformities, suboptimal outcomes result when conscientious and consistent physiotherapy is not the primary therapeutic modality and where surgical intervention is central in the treatment plan. Rarely, patients have died during infancy as a result of severe respiratory complications [47, 59]. Untreated or unrecognised psychosocial problems can have a very deleterious effect on functional outcomes and have a high association with substance abuse. Despite complexities and complications inherent to FBS, appropriate non-operative and operative interventions that consider the unique problems of the muscles can yield excellent functional and quality-of-life outcomes. Most individuals with FBS are high-functioning intellectually and, with proper early-life care, can lead normal, healthy, and independent lives.

\section{Conclusions}

FBS is a rare, complex, and poorly understood congenital craniofacial condition with challenging life-long physical and psychiatric implications. FBS is defined by pathognomonic craniofacial findings. Management must be proactive to avoid preventable complications and optimise the patient's functional and occupational status-not reactive maintenance. This fundamental difference in management is an important and often overlooked distinction, and many opportunities to help patients have been missed. Optimal care is probably best achieved through a combination of early craniofacial reconstructive surgery and intensive physiotherapy for most other problems. Much of the therapeutic focus is on the areas of fibrous tissue replacement, which are either operatively released or gradually stretched with physiotherapy to reduce contractures. Operative procedures and techniques that do not account for the unique problems of the muscle and fibrous tissue replacement have poor clinical and functional outcomes.

\section{Unresolved questions}

While basic science data are now available and add important information, significant gaps in the literature remain. Virtually no studies, outcomes data, discussion of psychiatric and physiological burdens, or critical discussion of therapeutic approaches are available. With data on genotype and phenotype correlations and translational data on functional consequences of observed allelic variations, it is foreseeable that great improvements in clinical care are possible.

Studies are specifically needed to evaluate the unique compound psychiatric burden of craniofacial deformities and limb malformations that impact fine motor function and ambulation. Evaluating the biochemical burden and gross physiological consequences of aberrant ATP functioning in FBS are especially important in developing targeted therapeutic interventions that can compensate for this pathophysiology and eventually to correct it. Research may also be warranted to evaluate a possible relationship of idiopathic hyperpyrexia and stress. Without substantive investigation of functional clinical questions concerning FBS, considerable, wide-scale improvement in the care of these patients is unlikely.

\section{Abbreviations}

ATP: Adenosine triphosphate; CLIFAHDD: Congenital contractures of the limbs and face, hypotonia, and developmental delay; FBS: Freeman-Burian syndrome; IRB: Institutional review board; MYH3: Embryonic myosin heavy chain gene; NALCN: Non-selective sodium leak channel gene; PIEZO2: Piezo 
type mechanosensitive ion channel component 2 gene; SHS: Sheldon-Hall syndrome; TNNT3 and TNNI2: Troponin T and I genes; TPM2: Tropomyosin beta chain gene

\section{Acknowledgements}

An early draft guideline was presented by MIP to the Pediatric Residents' Noon Conference, Robert C Byrd Health Sciences Center, West Virginia University School of Medicine, Morgantown, WV, USA, on 13 Dec 2006. The authors also wish to thank CM Poling, MS, for helpful manuscript review and the Rev. Alan Neal, David W Goetz, MD, PhD, and Greenbrier D Almond, MD, for early manuscript review and discussion. The authors remember the late Victor A McKusick, MD; Augusto L Portillo, MD; and Rigoberto RT Ramirez, $M D$, for their early manuscript review and discussion

\section{Funding}

No funding was received.

\section{Availability of data and materials}

Not applicable.

\section{Authors' contributions}

MIP drafted the manuscript, and CRD is the guarantor. MIP, CRD, and RLC revised the draft and approved the final manuscript.

\section{Authors' information}

MIP is Research Assistant in the Department of Applied Physiology, FSRG deGruyter-McKusick Institute of Health Sciences, Buckhannon, WV, USA. CRD is Clinical Professor of Plastic Surgery in the Department of Surgery, Georgetown University, Washington, DC, USA.

\section{Ethics approval and consent to participate}

Sponsored by Freeman-Sheldon Research Group, Inc., this review received institutional review board approval from FSRG IRB \#1.

\section{Consent for publication}

Informed consent from the patient pictured was obtained.

\section{Competing interests}

The authors declare that they have no competing interests.

\section{Publisher's Note}

Springer Nature remains neutral with regard to jurisdictional claims in published maps and institutional affiliations.

\section{Author details}

'FSRG deGruyter-McKusick Institute of Health Sciences, Buckhannon, USA.

${ }^{2}$ Department of Surgery, Georgetown University, Washington, DC, USA.

Received: 8 June 2018 Accepted: 21 December 2018

Published online: 10 January 2019

\section{References}

1. Poling MI, Dufresne CR. Revisiting the many names of Freeman-Sheldon syndrome. J Craniofac Surg. 2018;29(8):2176-8.

2. Poling MI, Dufresne CR. Head first, not feet first: Freeman-Sheldon syndrome as primarily a craniofacial condition. Cleft Palate Craniofac J. 2018;55(5):787-8.

3. Stevenson DA, Carey JC, Palumbos J, Rutherford A, Dolcourt J, Bamshad MJ. Clinical characteristics and natural history of Freeman-Sheldon syndrome. Pediatrics. 2006;117(3):754-62.

4. Freeman EA, Sheldon JH. Cranio-carpo-tarsal dystrophy: undescribed congenital malformation. Arch Dis Child. 1938;13:277-83.

5. Burian F. The "whistling face" characteristic in a compound cranio-faciocorporal syndrome. Br J Plast Surg. 1963;16:140-3.

6. Wynne-Davies R, Gormley J. The prevalence of skeletal dysplasias: an estimate of their minimum frequency and the number of patients requiring orthopaedic care. J Bone Joint Surg Br. 1985;67-B(1):133-7.

7. MacLeod P, Patriquin $\mathrm{H}$. The whistling face syndrome--cranio-carpo-tarsal dysplasia. Report of a case and a survey of the literature. Clin Pediatr (Phila). 1974;13(2):184-9.

8. Attia A, Suleman M, Al Nwasser AA. Freeman-Sheldon syndrome with respiratory failure: a case report. Respiratory Medicine CME. 2008;1:274-7.
9. Estrada R, Rosenfeld W, Salazar JD, Jhaveri R. Freeman-Sheldon syndrome with unusual hand and foot anomalies. J Natl Med Assoc. 1981;73(7):664-7.

10. Fitzsimmons JS, Zaldua V, Chrispin AR. Genetic heterogeneity in the Freeman-Sheldon syndrome: two adults with probable autosomal recessive inheritance. J Med Genet. 1984;21(5):364-8.

11. Toydemir RM, Rutherford A, Whitby FG, Jorde LB, Carey JC, Bamshad MJ. Mutations in embryonic myosin heavy chain (MYH3) cause Freeman-Sheldon syndrome and Sheldon-hall syndrome. Nat Genet. 2006;38(5):561-5.

12. Tajsharghi $H$, Kimber $E$, Kroksmark A, Jerre R, Tulinius M, Oldfors A Embryonic myosin heavy-chain mutations cause distal arthrogryposis and developmental myosin myopathy that persists postnatally. Arch Neurol. 2008;65(8):1083-90.

13. Racca AW, Beck AE, McMillin MJ, Korte FS, Bamshad MJ, Regnier M. The embryonic myosin R672C mutation that underlies Freeman-Sheldon syndrome impairs cross-bridge detachment and cycling in adult skeleta muscle. Hum Mol Genet. 2015;24(12):3348-58

14. Walklate J, Vera C, Bloemink MJ, Geeves MA, Leinwand L. The most prevalent Freeman-Sheldon syndrome mutations in the embryonic myosin motor share functional defects. J Bio Chem. 2016:291(19):10318-31.

15. Bell KM, Kronert WA, Guo Y, Rao D, Huang A, Bernstein SI, Swank DM. The muscle mechanical basis of Freeman-Sheldon syndrome. 83-Plat. 2016:14a.

16. Portillo AL, Poling MI, McCormick RJ. Surgical approach, findings, and 8-year follow-up in a 21-year-old female with Freeman-Sheldon syndrome presenting with blepharophimosis causing near-complete visual obstruction. J Craniofac Surg. 2016;27(5):1273-6.

17. Gurnett CA, Alaee F, Desruisseau D, Boehm S, Dobbs MB. Skeletal muscle contractile gene (TNNT3, MYH3, TPM2) mutations not found in vertical talus or clubfoot. Clin Orthop Relat Res. 2009;467(5):1195-200.

18. Beck AE, McMillin MJ, Gildersleeve HI, Shively KM, Tang A, Bamshad MJ. Genotype-phenotype relationships in Freeman-Sheldon syndrome. Am J Med Genet A. 2014;164(11):2808-13.

19. Chong JX, McMillin MJ, Shively KM, Beck AE, Marvin CT, Armenteros JR, Buckingham KJ, Nkinsi NT, Boyle EA, Berry MN, et al. De novo mutations in NALCN cause a syndrome characterized by congenital contractures of the limbs and face, hypotonia, and developmental delay. Am J Hum Genet. 2015:96(3):462-73

20. Schrander-Stumpel C, Fryns JP, Beemer FA, Rive FA. Association of distal arthrogryposis, mental retardation, whistling face, and Pierre Robin sequence: evidence for nosologic heterogeneity. Am J Med Genet. 1991; 38(4):557-61.

21. Zampino G, Conti G, Balducci F, Moschini M, Macchiaiolo M, Mastroiacovo P. Severe form of Freeman-Sheldon syndrome associated with brain anomalies and hearing loss. Am J Med Genet. 1996;62:293-6.

22. Sung SS, Brassington AME, Krakowiak PA, Carey JC, Jorde LB, Bamshad MJ. Mutations in TNNT3 cause multiple congenital contractures: a second locus for distal arthrogryposis type 2B. Am J Hum Genet. 2003;73:212-4.

23. Tajsharghi H, Kimber E, Holmgren D, Tulinius M, Oldfors A. Distal arthrogryposis and muscle weakness associated with a betatropomyosin mutation. Neurology. 2007:68:772-5.

24. Robinson P, Lipscomb S, Preston LC, Altin E, Watkins H, Ashley CC, Redwood CS. Mutations in fast skeletal troponin I, troponin T, and betatropomyosin that cause distal arthrogryposis all increase contractile function. FASEB J. 2007:21:896-905

25. McMillin MJ, Beck AE, Chong JX, Shively KM, Buckingham KJ, Gildersleeve HIS, Aracena MI, Aylsworth AS, Bitoun P, Carey JC, Clericuzio CL, Crow YJ, et al. Mutations in PIEZO2 cause Gordon syndrome, Marden-Walker syndrome, and distal arthrogryposis type 5. Am J Hum Genet. 2014;94:734-44.

26. Robbins-Furman P, Hecht JT, Rocklin M, Maklad N, Greenhaw G, Wilkins I. Prenatal diagnosis of Freeman-Sheldon syndrome (whistling face). Prenat Diagn. 1995;15(2):179-82.

27. Hegde SS, Shetty MS, Rama Murthy BS. Freeman-Sheldon syndrome-prenatal and postnatal diagnosis. Indian J Pediatr. 2010;77(2):196-7.

28. Hague J, Delon I, Brugger K, Martin H, Abbs S, Park SM. Molecularly proven mosaicism in phenotypically normal parent of a girl with Freeman-Sheldon syndrome caused by a pathogenic MYH3 mutation. Am J Med Genet A. 2016;170(6):1608-12

29. Poling MI, Dufresne CR. Anaesthesia recommendations for FreemanBurian syndrome. OrphanAnesthesia. 2018; Available at: https://www. orphananesthesia.eu/en/rare-diseases/published-guidelines/cat_view/ 61-rare-diseases/60-published-guidelines/229-freeman-buriansyndrome.html. 
30. Weinstein S, Gorlin RJ. Cranio-carop-tarsal dysplasia or the whistling face syndrome. Am J Dis Child. 1969;117(4):427-33.

31. Cervenka J, Gorlin RJ, Figalova P, Farkasova J. Craniocarpotarsal dysplasia or whistling face syndrome. Arch Otolaryngol. 1970;91(2):183-7.

32. Gross-Kieselstein E, Abrahamov A, Ben-Hur N. Familial occurrence of the FreemanSheldon syndrome: cranio-carpotarsal dysplasia. Pediatr. 1971;47(6):1064-7.

33. Rinsky LA, Bleck EE. Freeman-Sheldon ("whistling face") syndrome. J Bone Joint Surg Am. 1976;58(1):148-50.

34. Vaitiekaitis AS, Hornstein L, Neale HW. A new surgical procedure for correction of lip deformity in cranio-carpo-tarsal dysplasia (whistling face syndrome). J Oral Surg. 1979;37(9):669-72.

35. Laishley RS, Roy WL. Freeman-Sheldon syndrome: report of three cases and the anaesthetic implications. Can Anaesth Soc J. 1986;33(3 Pt 1):388-93.

36. Guyuron B, Winkler PA. Craniocarpotarsal dysplasia: the whistling face syndrome. Ann Plast Surg. 1988;20(1):86-8.

37. Marasovich WA, Mazaheri M, Stool SE. Otolaryngologic findings in whistling face syndrome. Arch Otolaryngol Head Neck Surg. 1989;115(11):1373-80.

38. Toydemir PB, Toydemir R, Bökesoy I. Whistling face phenotype without limb abnormalities. Am J Med Genet. 1999:86:86-7.

39. Güven $\mathrm{O}$, Tekin U, Hatipoğlu M. Surgical and prosthodontic rehabilitation in a patient with Freeman-Sheldon syndrome. J Craniofac Surg. 2010;21(5):1571-4.

40. Salati SA, Hussain M. Freeman-Sheldon syndrome. APSP J Case Rep. 2013:4:7.

41. Pahor AL. Whistling-face syndrome. Ear Nose Throat J. 1980;59(5):232-4.

42. Chamberlain RL, Poling MI, Portillo AL, Morales A, Ramirez RRT, McCormick RJ. Freeman-Sheldon syndrome in a 29-year-old female presenting with rare and previously undescribed features. BMJ Case Rep. 2015. https://doi.org/10. 1136/bcr-2015-212607

43. Bekir N, Bayraktaroglu Z, Coskun Y, Karaaslan C. Whistling face (FreemanSheldon) syndrome in two siblings. Turk J Pediatr. 1994;36(4):329-32.

44. Aren G, Yurdabakan Z, Ozcan I. Freeman-Sheldon syndrome: a case report. Quintessence Int. 2003;34(4):307-10.

45. Call WH, Strickland JW. Functional hand reconstruction in the whistling-face syndrome. J Hand Surg Am. 1981;6(2):148-51.

46. Wenner SM, Shalvoy RM. Two-stage correction of thumb adduction contracture in Freeman-Sheldon syndrome (craniocarpotarsal dysplasia). J Hand Surg Am. 1989:14(6):937-40.

47. Rintala AE. Freeman-Sheldon's syndrome, cranio-carpo-tarsal dystrophy. Acta Paediatr Scan. 1968:57:553-6.

48. Savini R, Gualdrini G. Report on two cases of Freeman-Sheldon syndrome (whistling face). Ital J Orthop Traumatol. 1980;1:105-15.

49. Duggar RG Jr, DeMars PD, Bolton VE. Whistling face syndrome: general anesthesia and early postoperative caudal analgesia. Anesth. 1989;70(3):545-7.

50. Munro HM, Butler PJ, Washington EJ. Freeman-Sheldon (whistling face) syndrome. Anaesthetic and airway management. Paediatr Anaesth. 1997;7(4):345-8.

51. Agritmis A, Unlusoy O, Karaca S. Anesthetic management of a patient with Freeman-Sheldon syndrome. Paediatr Anaesth. 2004;14(10):874-7.

52. Madi-Jebara S, El-Hajj C, Jawish D, Ayoub E, Kharrat K, Antakly MC Anesthetic management of a patient with Freeman-Sheldon syndrome: case report. J Clin Anesth. 2007;19(6):460-2.

53. McCormick RJ, Poling MI, Chamberlain RL. Bilateral patellar tendon-bearing Symes-type prostheses in a severe case of Freeman-Sheldon syndrome in a 21-year-old woman presenting with uncorrectable equinovarus. BMJ Case Rep. 2015. https://doi.org/10.1136/bcr-2015-211338.

54. Richa FC, Yazbeck PH. Anaesthetic management of a child with FreemanSheldon syndrome undergoing spinal surgery. Anaesth Intensive Care. 2008; 36(2):249-53.

55. Vas $L$, Naregal $P$. Anaesthetic management of a patient with Freeman Sheldon syndrome. Paediatr Anaesth. 1998;8(2):175-7.

56. Viehmeyer S, Gabriel P, Bauer K, Bauer S, Sodian R, Hilberath JN. Anesthetic considerations for an adult patient with Freeman-Sheldon syndrome undergoing open heart surgery. Case Rep Anesthesiol. 2018;2018:7862327. https://doi.org/10.1155/2018/7862327.

57. Boehm S, Limpaphayom N, Alaee F, Sinclair MF, Dobbs MB. Early results of the Ponseti method for the treatment of clubfoot in distal arthrogryposis. J Bone Joint Surg Am. 2008;90(7):1501-7.

58. McCormick RJ, Poling MI, Portillo AL, Chamberlain RL. Preliminary experience with delayed non-operative therapy of multiple hand and wrist contractures in a woman with Freeman-Sheldon syndrome at ages 24 and 28 years. BMJ Case Rep. 2015. https://doi.org/10.1136/bcr-2015-210935.

59. Mustacchi Z, Richieri-Costa A Frota-Pessoa O. The Freeman-Sheldon syndrome. Rev Brazil Genet. 1979;2(4):259-66.

Ready to submit your research? Choose BMC and benefit from:

- fast, convenient online submission

- thorough peer review by experienced researchers in your field

- rapid publication on acceptance

- support for research data, including large and complex data types

- gold Open Access which fosters wider collaboration and increased citations

- maximum visibility for your research: over $100 \mathrm{M}$ website views per year

At $\mathrm{BMC}$, research is always in progress.

Learn more biomedcentral.com/submissions 